\title{
LAS REMESAS ENVIADAS DESDE ESAPAÑA: ANÁLISIS DE SU IMPACTO EN LAS ECONOMÍAS RECEPTORAS
}

\author{
Rosa María Verdugo Matés \\ Departamento de Economía Aplicada. Universidade de Santiago de Compostela \\ rosa.verdugo@usc.es \\ María José Piñeira Mantiñán \\ Departamento de Geografía. Universidade de Santiago de Compostela \\ mariajose.pineira@usc.es
}

\section{RESUMEN}

España fue durante las décadas de 1960 y 1970 emisora de emigrantes y receptora de remesas. Actualmente, es una importante receptora de inmigrantes y emisora de remesas. En este artículo, tras sintetizar estos cambios en los flujos migratorios, realizamos algunas consideraciones teóricas sobre las remesas. A continuación, analizamos la situación actual del pago de remesas realizado desde la economía española, cuantificando su volumen e identificando las principales nacionalidades que efectúan los envíos. Para finalizar, para esas nacionalidades ponderamos la importancia de las remesas enviadas desde todo el mundo.

Palabras clave: Remesas, emigrantes, inmigrantes, extranjeros, balanza de pagos.

\section{ABSTRACT}

During the 1960s and '70s, Spain sent out emigrants and received remittances. Today, it is an important receiver of immigrants and issuer of remittances. In this article, after synthesizing these changes in migratory flows, we performed some theoretical considerations about remittances. Next, we analyzed the present situation of the payment of remittances from the Spanish economy, quantifying its volume and identifying the main nationalities that perform them. To finalize, we considered the importance for those nations of the remittances they receive from around the world. 
Key words: Remittances, emigrants, immigrants, foreigners, balance of payments.

\section{INTRODUCCIÓN}

Son numerosas las investigaciones que demuestran que existe una correlación entre las condiciones económicas de un territorio y su estructura demográfica, en cuanto que los movimientos de la población están influenciados por las diferencias espaciales en las oportunidades de empleo (Zelinsky, 1971; Zamora, 2003). De este modo, un país se convierte en emisor de emigrantes cuando atraviesa por una coyuntura de crisis económica y en receptor de trabajadores extranjeros cuando experimenta una situación de crecimiento económico. En este sentido, España no es una excepción.

Finalizada la Segunda Guerra Mundial se produce una reactivación económica sin precedentes en los países del centro y norte de Europa, de forma que en el período 1950-1973 la variación anual media del PIB real fue del 4,6\% y la del PIB real per cápita fue del 3,8\% (Crafts y Toniolo, 1996). En ese mismo período, estos países concluyeron su transición demográfica, lo que se tradujo en una desaceleración del crecimiento de su población, que sólo registró una variación anual media del 0,3\% (Crafts y Toniolo, 1996). En este contexto económico y demográfico, la demanda de trabajo en los países del centro y norte de Europa superó a la oferta interna, por lo que estas economías se vieron obligadas a recurrir al empleo de trabajadores extranjeros que, en gran medida, llegaron de los países del sur de Europa, fundamentalmente de España, Grecia, Italia y Portugal (Seers, 1981: 27), donde el crecimiento económico era mucho más moderado y el crecimiento poblacional más elevado ${ }^{1}$. Desde el punto de vista económico estos flujos migratorios fueron beneficiosos tanto para los países receptores como para los emisores. Los receptores se beneficiaron de unas tasas de crecimiento que no hubieran sido posibles sin el aporte de esta fuerza de trabajo extranjera, que además ocupó los peores puestos de trabajo favoreciendo así el ascenso laboral de los autóctonos. Por su parte, los países emisores vieron aliviada su situación de desempleo y subempleo y utilizaron la llegada de remesas para impulsar el proceso de industrialización. De todas formas, y a pesar de la necesidad de la fuerza de trabajo extranjera que existía en los países más desarrollados de Europa, su llegada, al igual que ocurre hoy en día en nuestro país, no estuvo exenta de reacciones xenófobas y racistas (Berger y Mohr, 2002).

Pero este modelo de crecimiento económico entró en crisis tras el alza de los precios del petróleo del año 1973. En este contexto, los países del centro y norte de Europa empezaron a registrar unas elevadas y crecientes tasas de desempleo, lo que interrumpió la demanda de fuerza de trabajo extranjera. Además, el desempleo afectó más duramente a los extranjeros, de forma que en las economías desarrolladas se comenzaron a poner en marcha políticas de retorno y a endurecer la legislación que regulaba la entrada, la permanencia y el trabajo de

1 El premio nobel de economía Gary S. Becker vinculó la transición demográfica al proceso de crecimiento económico, defendiendo que en los países donde se culmina la I Revolución Industrial también se da un cambio en las pautas demográficas de su población. Su teoría aparece magistralmente expuesta en Becker, Gary S. (1960): «An Economic Analysis of Fertility», en Demographic and Economic Change in Developed Countries (Becker, Gary S.; Duesenberry, James S.; Okun, Bernard). Princeton, N.J. Princeton University Press, 225-256. 
los extranjeros (Mármora: 2002, 284-295). Al mismo tiempo, el sentimiento de rechazo a los extranjeros se acentuó, ya que el auge del desempleo provocó que los autóctonos estuvieran dispuestos a ocupar los puestos de trabajo que ocupaban los extranjeros.

Las economías capitalistas europeas sólo mostraron signos de recuperación a mediados de la década de 1980. Pero una vez superada la coyuntura de crisis no se volvieron a producir corrientes significativas de expulsión de trabajadores en el sur de Europa. Por una parte, los estados receptores dejaron de demandar fuerza de trabajo extranjera como en el pasado y comenzaron a endurecer su legislación de extranjería y, por otra parte, los cambios económicos, políticos y sociales que se produjeron en los estados del sur de Europa favorecieron la permanencia de los autóctonos (Verdugo Matés et al., 2004a). En el ámbito económico, la entrada de Grecia en la Comunidad Económica Europea en el año 1981 y la de los estados español y portugués en 1986, canalizó una importante cantidad de fondos estructurales hacia esas economías, lo que incidió sobre su crecimiento económico y creación de empleo. En el ámbito político-social, la finalización de la dictadura salazarista portuguesa en 1974 y muerte de Franco en 1975 abrieron expectativas de cambio tras la puesta en marcha de estados de bienestar similares a los existentes en los países desarrollados de Europa.

Estos cambios económicos, políticos y sociales provocaron un giro en la tendencia de los flujos migratorios en nuestro país. A lo largo de este artículo analizaremos el volumen de población extranjera que llegó a España, así como las remesas enviadas por los emigrantes a sus países de origen, el esfuerzo realizado por cada nacionalidad en el envío de remesas o el peso de las mismas en el PIB de cada país.

\section{ESPAÑA: DE PAÍS EMISOR A RECEPTOR DE INMIGRANTES}

\section{II.1. La llegada de inmigrantes desde los años 1990}

Hasta comienzos de la década de 1980, la condición periférica de la economía española en Europa provocaba que se registraran pocas entradas de extranjeros en nuestro país. Y los que entraban, no lo hacían para incorporarse al mercado laboral. En esa época, la población extranjera estaba formada, principalmente, por dos flujos. El primero, constituido por jóvenes estudiantes, básicamente iberoamericanos, que venían a cursar programas de postgrado o cursos de especialización universitaria. El segundo, formado por turistasresidentes, en su mayoría jubilados, sobre todo del Reino Unido, Alemania y Suecia, que se instalaban en la costa mediterránea atraídos por el mayor poder adquisitivo que tenían sus ingresos en la economía española y por el clima cálido de esas regiones mediterráneas (Rodríguez Rodríguez: 2005, 24-34). Así, en el año 1975, residían 164.000 extranjeros en España, de los cuales 114.000 eran oriundos de los países desarrollados (en su gran mayoría turistas-residentes) y sólo 50.000 procedían de países en vías de desarrollo (mayoritariamente estudiantes extranjeros). En la década de 1980 comienzan a llegar, pero aún tímidamente, otros contingentes de extranjeros, como el constituido por iberoamericanos que huyen de las dictaduras de sus países, y que vienen a España por los vínculos históricos y culturales existentes, o el formado por ciudadanos de la Europa del este que escapan del caos generado tras el desmembramiento del bloque comunista europeo. A pesar de 
estos constantes flujos migratorios, en 1985 el número total de extranjeros que residían en el territorio español era de $242 \mathrm{mil}^{2}$.

Posteriormente, la entrada de España en la Comunidad Económica Europea en 1986 junto con la recuperación económica de mediados de la década de 1980 de las economías capitalistas europeas en general y de la española en particular, provocaron que España comenzase a perfilarse como un destino atractivo para la inmigración laboral. Las actividades que generaron más oportunidades para los inmigrantes fueron la construcción -en cierta medida gracias a la llegada de fondos estructurales europeos que se destinaron a la realización de obras de infraestructuras- y la agricultura -por el impulso de los cultivos mediterráneos en los que los países europeos comunitarios eran deficitarios-, creándose en ambas actividades un elevado número de puestos de trabajo poco cualificados y mal remunerados que, al no ser cubiertos por los autóctonos, posibilitó la llegada de trabajadores extranjeros.

Otros factores que favorecieron la intensificación de la entrada de inmigrantes fueron el peso relativo de la economía informal en diversos sectores, la existencia de una legislación más permisiva con la entrada de extranjeros que la existente en otros países de la Europa comunitaria y la proximidad geográfica y los vínculos históricos con los países que actualmente son los principales emisores de población (López Sala, 2005: 171-175). Por su parte, la existencia de un importante sector informal en la economía española favoreció la llegada y sobre todo la permanencia de los inmigrantes, ya que el trabajo en la economía sumergida constituía una fuente de ingresos para aquellos que o bien entraban indocumentados en el territorio español o bien caían en una situación de irregularidad administrativa. Por lo que respecta a la legislación de extranjería, la reducida presencia de extranjeros provocaba que los requisitos exigidos fueran muy laxos en nuestro país, mientras que en los países desarrollados de Europa ya se comenzaba a endurecer la legislación, firmándose en el año 1985 los Acuerdos de Schengen por Alemania, Francia, Bélgica, Holanda y Luxemburgo. Como resultado, las fronteras españolas se convirtieron en la puerta de entrada de muchos inmigrantes que, en algunos casos, veían a nuestro país como la vía para llegar a otros destinos europeos. Además, los $14 \mathrm{Km}$. que separan las costas españolas de las africanas hicieron que nuestro territorio se convirtiera en el lugar natural de entrada para los ciudadanos de África, actualmente uno de los focos de emisión de emigrantes más activos. Por último, la lengua común también operó como factor de atracción para los nacionales de países sudamericanos, colectivo que además se ha visto desde siempre favorecido por un trato preferente en la legislación de extranjería, la cual tiene como objetivo no declarado potenciar estas procedencias frente a otras, sobre todo las africanas de religión musulmana (Izquierdo et al., 2003 y Verdugo et al., 2004b).

\section{II.2. Evolución de los residentes extranjeros}

Como consecuencia de los factores explicados anteriormente, a partir de la década de 1990 se observa un aumento del número de extranjeros en nuestro país. Según los datos ofrecidos por el Ministerio de Trabajo y Asuntos Sociales, España pasó de 360.655

2 Datos calculados por el colectivo IOÉ, a partir de información obtenida de la Comisaría General de Documentación, de la Dirección General de Migraciones y del Instituto Nacional de Estadística. 
residentes extranjeros en 1991 a 1.109 .060 en 2001, alcanzó casi los 2 millones en 2004 (1.977.291 extranjeros) y se situó en 4.791 .232 a 31 de Diciembre de 2009³. En la Figura 1a podemos visualizar la evolución experimentada por el número de residentes extranjeros en la U.E.-15 y en España durante el período 1995-2008. Esta comparativa evidencia el crecimiento de la inmigración en el territorio español, de forma que si en el conjunto de la U.E.-15 el número de extranjeros pasó de 17 a 29 millones, en España se incrementó de 500.000 a 5,5 millones, es decir, el 40\% del incremento de los inmigrantes en la U.E-15 se concentró en el territorio español ${ }^{4}$. Durante este período, el incremento interanual de los extranjeros en la U.E-15 se mantuvo sin grandes variaciones en el 5\%, mientras que en el caso español esta tasa es muy superior, con valores que están por encima del $15 \%$ en casi todo el período analizado (Figura 1b).

Figura 1a

EVOLUCIÓN DEL NÚMERO DE RESIDENTES EXTRANJEROS (EN MILLONES)

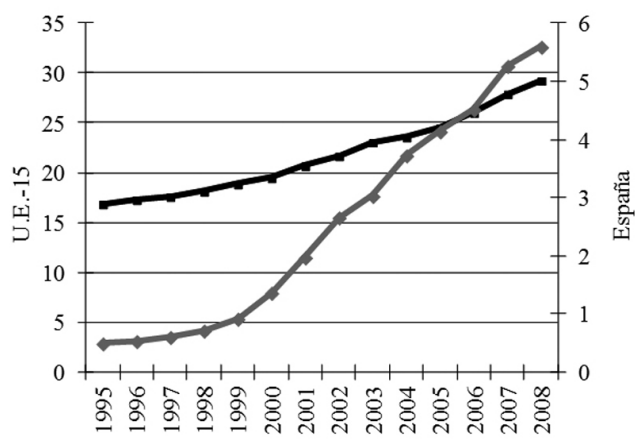

-U.E.-15
Figura $1 \mathrm{~b}$
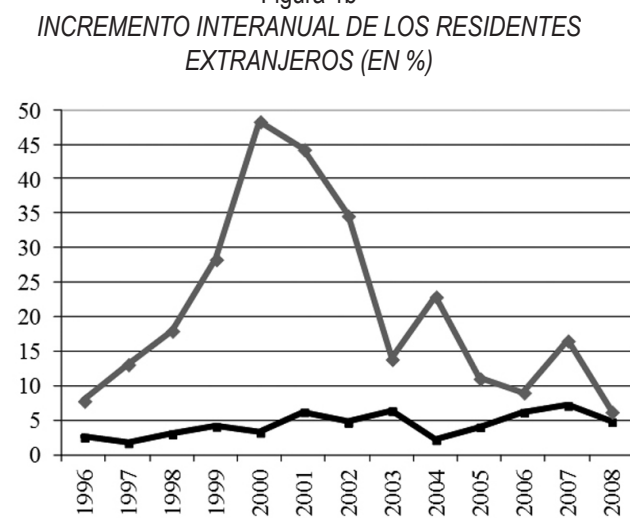

$\leftarrow$ U.E.-15 España

Fuente: Elaboración propia a partir de Internacional Migration Database (OCDE) (1995-2008).

Estos cambios cuantitativos también estuvieron acompañados de otros de carácter cualitativo, de forma que la composición de las procedencias de los residentes extranjeros se ha visto modificada. Según los datos del Ministerio de Trabajo e Inmigración, en 1995 predominaban los extranjeros procedentes de Marruecos (15\% del total), seguidos por los oriundos del Reino Unido (13\%), Alemania (8\%), Portugal (7\%) y Francia (6\%), concentrando entre los cinco el 50\% del total de extranjeros. En el año 2009 Marruecos sigue ocupando el primer puesto (con el $16 \%$ del total), pero las siguientes posiciones son para Rumania (16\%), Ecuador (9\%), Colombia (6\%) y Reino Unido (5\%), acumulando entre los cinco la mitad de los

3 Estos son datos publicados por el Ministerio de Trabajo e Inmigración, donde sólo se registran los extranjeros con tarjeta de residencia en vigor. Sin embargo, según el Padrón Municipal de Habitantes, donde están inscritos buena parte de los extranjeros en situación irregular, a 1 de enero de 2010 había 5.747.734 extranjeros residiendo en el territorio español, lo que situaría el número de indocumentados en un millón.

4 La estadística de Internacional Migration Database de la OCDE utiliza los datos del Padrón Municipal de Habitantes. 
extranjeros. Estas transformaciones en el peso de las nacionalidades de los residentes extranjeros reflejan el cambio de papel que ha experimentado nuestro país en los flujos migratorios internacionales: si en el pasado nuestro territorio fundamentalmente receptor de turistasresidentes procedentes de los países europeos desarrollados y de estudiantes universitarios sudamericanos, hoy a estos colectivos, que no han dejado de incrementarse, se ha unido otro, el constituido por inmigrantes trabajadores procedentes de los países en desarrollo. Así, los tradicionales destinos turísticos de la costa mediterránea han seguido funcionando como lugares de atracción de turistas-residentes y, al mismo tiempo, se han convertido en zonas de atracción de inmigrantes trabajadores. Efectivamente, el auge del turismo ha impulsado el desarrollo de las actividades vinculadas al sector turístico, como los restaurantes y los bares, creándose puestos de trabajo que por sus condiciones salariales y laborales no eran atractivos para los autóctonos y se han ido ocupando por la fuerza de trabajo extranjera (Cànoves Valiente y Blanco Romero: 2009, 267-268).

Con el fin de visualizar la importancia de cada una de las nacionalidades de extranjeros que residen en nuestro territorio, presentamos en la Figura 2 el peso de cada una de ellas en relación a la población residente en su país de origen. Los valores más elevados son para Rumania, Ecuador, Guinea Ecuatorial, Bulgaria, Bolivia y Marruecos, que tienen más de 2.000 emigrantes residiendo en nuestro país por cada 100.000 habitantes residiendo en su país de origen.

Figura 2

EMIGRANTES A ESPAÑA POR CADA 100.000 RESIDENTES EN SU PAÍS DE ORIGEN

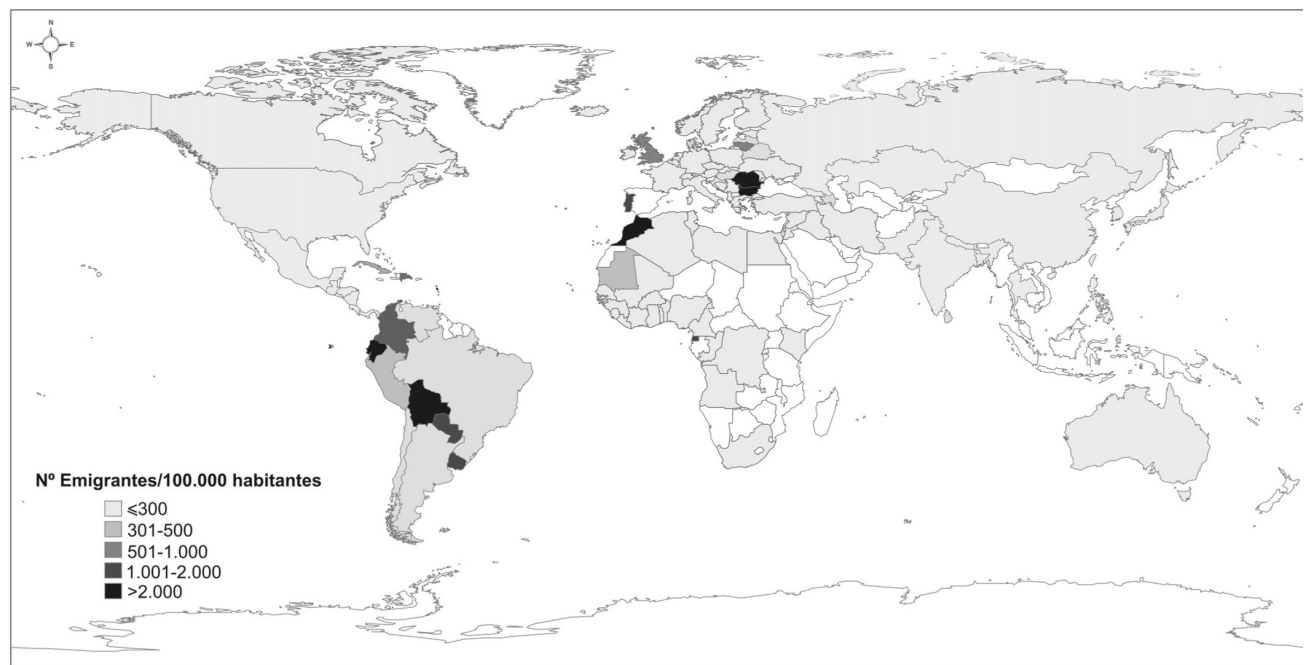

Fuente: Elaboración propia a partir de Padrón Municipal de Habitantes 2010 (INE).

\section{II.3. El impacto de la inmigración sobre la economía y la demografía española}

El incremento experimentado por el número de trabajadores extranjeros en la economía española ha permitido unas tasas de crecimiento económico que no hubieran sido posibles sin el aporte de esta fuerza de trabajo inmigrante. En una investigación realizada por la Ofi- 
cina Económica del Presidente del Gobierno para el período 1996-2006 se aportan datos que demuestran la importancia del trabajo inmigrante en el crecimiento económico español. Se dice, por ejemplo: «En los últimos diez años, más de un punto porcentual del crecimiento medio anual se puede asignar a la inmigración, es decir, casi el 30\%. En los últimos 5 años, este efecto ha sido todavía superior, superando el 50\% (1,6\% sobre 3,1\%)». Y también: «La inmigración ha tenido un impacto neto sobre la renta per capita de 3 puntos en el periodo 1996-2005 y de 2 puntos en los últimos cinco años. Esto equivale a 623 por persona» (Sebastián, 2006). Recientemente, la Obra Social la Caixa ha publicado un estudio de donde se siguen constatando el impacto positivo de los inmigrantes en la economía española (Moreno Fuentes y Bruquetas Callejo, 2011).

Además de incidir sobre el crecimiento económico, los inmigrantes han contribuido positivamente en las cuentas del Estado. En una investigación realizada para la economía española en el año 1998, se calculó que la diferencia entre ingresos y gastos públicos imputados a los inmigrantes era de 750 mil euros $^{5}$ a favor del Estado (Aparicio Gómez, 2003: 100). Si dividimos esa cantidad entre los 748.958 extranjeros que residían en el territorio español en el año 1998, cada inmigrante supuso un saldo positivo de 1.565 euros a favor del Estado.

Sin embargo, la contribución del extranjero no se limita al país de destino, sino que también afecta a su país de origen, fundamentalmente a través del envío de remesas, siendo poco abundantes las investigaciones realizadas en este sentido por los investigadores españoles. Un simple dato nos revela la importancia que juega la economía española en el envío de remesas: según el Banco Mundial en el año 2009 España envió 12.246 millones de dólares en remesas, y ocupó el octavo puesto mundial por detrás de Estados Unidos, Arabia Saudita, Suiza, Federación de Rusia, Alemania, Países Bajos e Italia.

Fuera del ámbito económico, los inmigrantes también han contribuido positivamente en el ámbito demográfico. En la mencionada investigación realizada por la Oficina Económica del Presidente del Gobierno se dice: «El escenario demográfico que los principales organismos internacionales asignaban a España en 1996 era bastante sombrío. Así, por ejemplo, las previsiones de Naciones Unidas nos situaban en 2050 con 30 millones de personas en España. Hoy, las previsiones del INE, sujetas a gran incertidumbre por esta nueva realidad demográfica, nos sitúan en torno a los 53 millones de habitantes en 2050» ó «En los últimos años, la población en España ha experimentado tasas de crecimiento desconocidas en su historia. En el periodo 2000-2005 la población de España aumentó en más de 3 millones de personas, más que en los 20 años precedentes. El ritmo anual de crecimiento fue del 1,5\%, superior incluso al del babyboom de los años 60 y al de los años de la posguerra» (Sebastián, 2006).

Los países de la Unión Europea son conscientes de que las salidas de emigrantes de los países subdesarrollados no cesarán hasta que mejoren las condiciones económicas, políticas y sociales de los países emisores. Por ese motivo uno de los tres ejes de la política comunitaria en materia de inmigración es el desarrollo de estos países mediante políticas de Cooperación y Ayuda al Desarrollo. Sin embargo, los esfuerzos materiales realizados hasta lo de ahora en este punto han sido escasos, de forma que hoy día las remesas de los inmigrantes alcanzan para muchos países del Tercer Mundo una mayor dimensión que la Ayuda Oficial al Desarrollo o que la Inversión Extranjera Directa. En este artículo vamos a analizar la evo-

\footnotetext{
5 En la publicación figura la cuantía en pesetas (196.122.965.222 pesetas).
} 
lución y la situación actual del pago de remesas realizado desde la economía española, cuantificando su volumen e identificando las principales nacionalidades que efectúan los envíos. A continuación, para esas nacionalidades analizamos la importancia de las remesas enviadas desde todos los países del mundo. Para finalizar, comparamos la llegada de remesas con otras variables como la Ayuda Oficial al Desarrollo o la Inversión Extranjera Directa. Pero antes de desarrollar estas cuestiones vamos a realizar algunas consideraciones sobre las remesas.

\section{ALGUNAS CONSIDERACIONES TEÓRICAS SOBRE LAS REMESAS}

Antes de iniciar el análisis del flujo de remesas enviadas desde la economía española, vamos a desarrollar algunos aspectos teóricos relativos a las remesas. En primer lugar, aportaremos diferentes definiciones del concepto remesas, resumiremos las principales corrientes que explican las motivaciones que tiene el emigrante para remesar y analizaremos las diferentes vías de envío de remesas, indicando los aspectos positivos y negativos de cada una de ellas. A continuación, expondremos los resultados de algunos estudios que analizan la relación entre remesas y desarrollo.

\section{III.1. Las remesas: Definición y canales de envío}

El Banco Mundial aplica el concepto de remesa a tres tipos de flujos monetarios: las remesas de los trabajadores migrantes (denominadas remesas personales), las remuneraciones de los empleados, y las transferencias financieras y en productos de los emigrantes. Otros investigadores utilizan una definición más amplia que incluye todo tipo de donativos personales en dinero o en productos, mientras que otros estudiosos consideran necesario tener en cuenta las remesas sociales, que son definidas como el conjunto de ideas, prácticas, actitudes, visión y capital social que de forma voluntaria o involuntaria el migrante transfiere a su país de origen (Levitt, Peggy, 2001). Según esta visión, las remesas sociales desempeñan un papel fundamental en la formación de la comunidad transnacional, proyectan el impacto de las migraciones en las relaciones internacionales y estimulan la sinergia de las comunidades locales, regionales, nacionales e internacionales. Ahora bien, la mayoría de las investigaciones sobre las remesas tienen en cuenta la definición del Banco Mundial, ya que este organismo internacional publica anualmente datos relativos al envío y recepción de remesas para casi la totalidad de países del mundo.

Existen dos grandes corrientes de pensamiento que explican las motivaciones que tiene el emigrante para realizar el envío de remesas. La primera tiene en cuenta cuestiones sociodemográficas (relaciones familiares) y el altruismo (Elbadawi y Rocha, 1992). Dentro de esta corriente hay teorías que consideran las remesas como una variable endógena que depende directamente del salario del emigrante y de su propensión a ahorrar (Djajic, 1986). Otras teorías defienden que las remesas forman parte de un contrato entre el emigrante y su familia, donde el bienestar de la familia forma parte de la función de utilidad del emigrante (Chami et al., 2003). La segunda corriente de pensamiento defiende que el envío de remesas es una decisión de inversión por un agente económico racional que analiza las opciones en el país de origen y de residencia antes de invertir (Lucas y Stark, 1985). Realmente, estas dos corrientes de pensamiento son complementarias, pero tiene una gran importancia para el país emisor de 
emigrantes saber hasta qué punto tiene más peso la variable socio demográfica-altruista o la económico-racional, ya que en el caso de predominar la segunda el país de origen del emigrante puede llevar a cabo una política para la captación de remesas ofreciendo ventajosas tasas de interés y de cambio, siendo esta política menos efectiva cuanto más predomine la variable socio demográfica-altruista. Además, cuando prevalece la variable altruista, la recepción de remesas para el país emisor de emigrantes peligra en el medio plazo si no se produce una renovación en el stock de emigrantes, ya que se constata que a medida que se prolonga la estancia del emigrante en el país de acogida los envíos tienden a disminuir (Elbadawi y Rocha, 1992).

Por lo que se refiere a las vías para la transferencia de remesas, podemos agruparlas en cuatro: bancos, empresas de transferencia, entidades no oficiales y familiares, amigos o conocidos. Los bancos y las empresas de transferencia son consideradas las vías oficiales del envío de remesas, ya que la legislación en vigor obliga a estas entidades a registrar todas y cada una de las transferencias realizadas, lo que posibilita conocer el volumen de envíos realizados desde cada país y saber cuál es su país de destino. Sin embargo, las otras dos vías operan en el ámbito informal y, en consecuencia, no tenemos datos oficiales del volumen de sus operaciones, por lo que hablamos de remesas informales.

Aparte de su carácter formal o informal, las diferentes vías de transferencia de remesas se diferencian por dos variables: las tasas cobradas por los envíos realizados y el tiempo de llegada de la remesa a su destino. Los bancos tienen unas tasas de envío muy inferiores a las empresas de transferencia, siendo en estas últimas altamente regresivas, es decir, proporcionadamente más altas para el envío de pequeñas cantidades. Sin embargo, el tiempo de llegada del envío es inmediato si se utilizan las empresas de transferencia mientras que los bancos demoran varios días, incluso una semana para algunos destinos. En algunas ocasiones los familiares que reciben las remesas tienen urgencia en su recepción, por lo que el emigrante cae en las manos de estas empresas de transferencia. En otras ocasiones, y sobre todo en los países del África Subsahariana, o bien el sistema bancario no tiene la suficiente diversificación como para llegar a los lugares de destino de las remesas o bien la posibilidad de tener una cuenta bancaria no está al alcance de todos los autóctonos, sobre todo de los más pobres, ya que el banco exige un depósito inicial de apertura excesivamente alto. Por todos estos motivos, el emisor de remesas tiene preferencia por las vías de envío no oficiales. En el caso de las entidades no oficiales las tasas son mucho más bajas y en el caso de los familiares, amigos o conocidos son inexistentes. Normalmente, las entidades no oficiales están formadas por un emigrante (al que vamos a denominar agente) que tiene una o varias personas de contacto en su país de origen (que vamos denominar comercial). El emigrante que quiere realizar un envío le entrega el dinero al agente y éste llama al comercial para indicarle la dirección donde tiene que realizar el envío y la cantidad de entrega. Es importante que el emigrante que realiza el envío tenga alguna referencia del agente, de ahí que, habitualmente, sean de la misma nacionalidad e incluso de la misma localidad.

\section{III.2. El papel de las remesas en el desarrollo de los países receptores}

En el año 2006 la Organización Internacional de las Migraciones celebró en Benin la Conferencia Ministerial de los Países Menos Avanzados sobre el impacto de las remesas en el desarrollo. En el informe final se enumeran los principales beneficios y costes potenciales 
de las remesas. En relación a los beneficios potenciales, el informe indica que las remesas son una fuente de divisa o moneda extranjera que facilita el comercio internacional y ayuda a financiar la deuda externa; son una fuente potencial de ahorro para la formación de capital y el desarrollo; mejoran el nivel de vida de los beneficiarios; reducen la desigualdad del ingreso; y reducen la pobreza. Por lo que respecta a los costes potenciales, se indica que las remesas presionan a los gobiernos en el sentido de realizar reformas para reducir los desequilibrios externos; reducen los ahorros de las familias beneficiarias afectando negativamente al crecimiento y al desarrollo; reducen el esfuerzo productivo de las familias beneficiarias y, por esta vía, afectan negativamente al crecimiento y al desarrollo; aumentan la desigualdad de los ingresos; y que las migraciones provocan la fuga de cerebros y prejuicios no compensados por las remesas.

En la década de 1990 comienza a ganar peso una corriente de pensamiento que defiende la tesis según la cual las remesas crean dependencia al país que las recibe porque elevan las expectativas materiales de sus habitantes y para satisfacerlas sus habitantes se centran en la estrategia de la emigración. También indican que las remesas mejoran el nivel de vida de los que las reciben pero no inciden significativamente en el desarrollo del país en su conjunto. En contraposición, otros investigadores sostienen que las remesas son la principal fuente externa de financiación del desarrollo, superando en cuantía en la mayoría de los países del Tercer Mundo a la Ayuda Oficial al Desarrollo o a la Inversión Extranjera Directa.

Sea como fuere, hay que evitar las generalizaciones y analizar el caso concreto de cada uno de los países receptores de remesas. En primer lugar, deberemos investigar cuales son las motivaciones que tiene cada nacionalidad para realizar el envío y cuáles son sus expectativas cuando lo realiza. Así, por ejemplo, si como decíamos anteriormente en el envío de remesas predomina la variable económica racional, el país receptor puede diseñar medidas de política económica para maximizar la recepción de remesas. En segundo lugar, deberíamos conocer las expectativas que tiene el emigrante en relación al uso de las remesas que envía para evitar que caiga en el desánimo y corte los envíos. En este sentido, un emigrante estará más estimulado a enviar remesas si su familia las utiliza para crear las condiciones necesarias para permitirles su propia supervivencia que si las emplea en consumo suntuoso. En tercer lugar, convendría saber cuáles son las vías de transferencia de las remesas, analizar las dificultades que tienen los emigrantes para enviarlas y sus familias para recibirlas, y tratar de establecer medidas favorables al envío y la recepción de las mismas. Y, por último, los países receptores deberían utilizar las remesas para llevar a cabo un proceso de crecimiento económico que mejorase las condiciones de vida de su población, evitando que continúe la sangría migratoria, para que emigrar se convirtiera en una opción vital y dejase de ser una obligación impuesta por la falta de expectativas en el país de origen. Incidiendo sobre este último aspecto, un elemento negativo de la inmigración sobre el desarrollo es la denominada fuga de cerebros. Así, investigaciones llevadas a cabo por Frédéric Docquier y Abdeslam Marfouk (Docquier y Marfouk, 2004) y Frédéric Docquier y Alok Bhargava (Docquier y Bhargava, 2006) para el período 1990-2000 concluyen que los diez mayores exportadores de trabajadores con diploma universitario proporcionalmente a su población son miembros de los Países Menos Desarrollados: Haití (82\%), Cabo Verde (69\%), Samoa (67\%), Gambia (65\%), Somalia (59\%), Eritrea (46\%), Mozambique (42\%), Sierra Leona (41\%), Liberia (37\%) y Madagascar (36\%). 
Actualmente, en los temas relacionados con la inmigración, las remesas y el desarrollo, también se hace referencia al término codesarrollo. Se trata de un concepto extenso, que abarca aspectos tan diversos como: 1) intervención sobre las remesas de los inmigrantes con el objetivo de realizar inversiones que redunden en un proceso de desarrollo en los países de origen; 2) la cooperación al desarrollo con los países de emigración -contando diversos grados de participación de miembros de las comunidades emigradas, pero realizada básicamente por parte de los gobiernos de las naciones receptoras de inmigrantes-; 3) acciones de retorno asistido de los inmigrantes a sus lugares de procedencia; 4) estrategias organizativas de las comunidades emigradas para promocionar el desarrollo en los lugares de origen; 5) líneas de acción política en las que se compromete a los gobiernos de los Estados emisores y receptores de población sobre aspectos de mutuo interés -como formación y educación; gestión de la innovación, difusión y cambio tecnológico, etc.; 6) apoyo a procesos de influencia positiva en la sociedad receptora de inmigrantes y de origen, con la participación activa de asociaciones del sector, unidas a otros actores; 7) hermanamientos entre las sociedades de origen y de recepción de los inmigrantes, implicando un conjunto de mutuos apoyos, preferencias y reconocimientos (Gómez Galán, 2008: 52-53).

Por otra parte, durante las últimas dos décadas, en relación con las remesas comienzan a surgir nuevas iniciativas de codesarrollo que tratan de vincular el envío de las mismas con el desarrollo de los países que las reciben. Seguramente el ejemplo más significativo sea el programa mexicano «Tres por uno»: el gobierno federal y las autoridades locales y regionales aportan cada uno un dólar por cada dólar transferido de la zona por los migrantes en EE.UU. Con los fondos reunidos se realizan inversiones para mejorar la enseñanza, la sanidad y las infraestructuras. Sólo en el año 2005, las Hometown Associations (asociaciones de comunidades de origen, HTA) mexicanas recaudaron unos 20 millones de dólares para proyectos en todo México, contribuyendo el gobierno y las autoridades locales 60 millones de dólares (Orozco y Rouse, 2007).

\section{EVOLUCIÓN DEL ENVÍO DE REMESAS DESDE LA ECONOMÍA ESPAÑOLA}

Las cifras oficiales relativas a la salida de remesas desde la economía española se publican en el Boletín Estadístico del Banco de España. En concreto, esta información se contabiliza dentro de las transferencias corrientes de la Balanza de Pagos. Dos son las principales limitaciones que presenta esta fuente estadística para el análisis de las remesas. La primera es que sólo existen datos anuales con un cierto grado de desagregación por países desde el año 2003. La escasa atención que mereció hasta hace poco tiempo esta partida dentro de la Balanza de Pagos española puede explicarse por el reducido volumen de remesas enviadas. Como decíamos anteriormente, hasta finales de la década de 1990 la presencia de residentes extranjeros en España era reducida, y estaba formada principalmente por turistas-residentes procedentes de países europeos desarrollados y por universitarios sudamericanos, colectivos ambos que no tenían como principal objetivo trabajar en nuestro país, por lo que los envíos de remesas que realizaban eran escasos. Una segunda limitación de estos datos es la infravaloración. De hecho, diferentes investigaciones indican que el volumen de remesas registrado por el Banco de España es muy inferior al volumen real. Por ejemplo, según un estudio publicado por el propio Banco de España la infravaloración rondaría el 20\% (Tello, 2006: 12). Tal 
y como se indica en ese estudio, para evitar las elevadas tasas que cobran las entidades dedicadas al envío de dinero, los inmigrantes canalizan siempre que pueden sus remesas a través de vías informales, bien aprovechando un viaje a su país, bien utilizando como intermediario a un familiar o conocido que va al país.

Teniendo en cuenta estas limitaciones vamos a analizar la evolución de los envíos de remesas efectuados desde la economía española desde el año 2003 hasta la actualidad. En este breve período de tiempo los pagos de remesas se duplicaron, pasando de 3.475 millones de euros el año 2003 a 8.449 millones de euros en 2007, bajando posteriormente hasta situarse en 7.213 millones de euros en el 2009 (Tabla 1). El aumento de los envíos de remesas está claramente correlacionado con el auge de los trabajadores inmigrantes en este mismo período, y su moderado descenso en el último bienio con el inicio de la actual crisis económica internacional.

Tabla 1

PAGOS DE REMESAS (2003-2009)

\begin{tabular}{|r|r|r|r|}
\hline & \multicolumn{1}{|c|}{$\begin{array}{c}\text { Remesas } \\
\text { (en millones de } € \text { ) }\end{array}$} & $\begin{array}{c}\text { Incremento } \\
\text { (en millones de } € \text { ) }\end{array}$ & $\begin{array}{c}\text { Incremento } \\
\text { (en \%) }\end{array}$ \\
\hline 2003 & 3.475 & & \\
\hline 2004 & 4.189 & 714 & 20,5 \\
\hline 2005 & 4.936 & 747 & 17,8 \\
\hline 2006 & 7.059 & 2.123 & 43,0 \\
\hline 2007 & 8.449 & 1.390 & 19,7 \\
\hline 2008 & 7.948 & -501 & $-5,9$ \\
\hline 2009 & 7.213 & -735 & $-9,2$ \\
\hline
\end{tabular}

Fuente: Elaboración propia a partir del Boletín Estadístico del Banco de España (varios años).

Los datos publicados en el Boletín Estadístico del año 2009 permiten conocer el destino geográfico de las remesas enviadas desde la economía española. La nacionalidad que registra un mayor volumen de envíos es Colombia, con 1.297 millones de euros, seguido por Ecuador con casi 1.000 millones de euros y por Bolivia con más de 600 millones de euros. A mucha distancia de todos ellos se encuentra un grupo de 17 países, registrando cada uno de ellos envíos inferiores a los 400 millones de euros (Tabla 2).

En principio, las nacionalidades que realizan más envíos deberían corresponderse con aquellas que tienen un mayor número de residentes en nuestro territorio, pero realmente no es eso lo que observamos. En 2009 la nacionalidad mayoritaria de los extranjeros era la marroquí, pero en relación al volumen de remesas enviadas Marruecos ocupa el puesto número cinco. Además, países que no figuraban entre las principales nacionalidades de residentes extranjeros en 2009 aparecen ahora entre las principales emisoras de remesas, como es el caso de Paraguay, Brasil, Senegal o Pakistán, cada una de ellas con un volumen de envíos superior a los 100 millones euros $^{6}$. Este resultado es coherente con la existencia de dos grandes grupos de extranjeros: el primero compuesto por extranjeros procedentes de países europeos desarrollados (mayoritaria-

6 En el año 2009 del total de extranjeros el 0,6\% son de Paraguay, el 1,2\% de Brasil, el 0,8\% de Senegal y el $1 \%$ de Pakistán. 
Tabla 2

ENVIOO DE REMESAS. PRINCIPALES PAÍSES (AÑO 2009)

\begin{tabular}{|l|r|r|r|}
\hline & Millones de $€$ & $\%$ sobre total & $\%$ acumulado \\
\hline Colombia & $1.297,6$ & 18,0 & 18,0 \\
\hline Ecuador & 962,5 & 13,3 & 31,3 \\
\hline Bolivia & 663,1 & 9,2 & 40,5 \\
\hline Rumanía & 363,6 & 5,0 & 45,6 \\
\hline Marruecos & 299,5 & 4,2 & 49,7 \\
\hline Paraguay & 299,5 & 4,2 & 53,9 \\
\hline Rep.Dominicana & 292,3 & 4,1 & 57,9 \\
\hline Perú & 256,7 & 3,6 & 61,5 \\
\hline Brasil & 249,5 & 3,5 & 64,9 \\
\hline Senegal & 128,3 & 1,8 & 66,7 \\
\hline Pakistán & 121,2 & 1,7 & 68,4 \\
\hline Filipinas & 92,7 & 1,3 & 69,7 \\
\hline Resto & $2.186,5$ & 30,3 & 100,0 \\
\hline TOTAL & $\mathbf{7 . 2 1 3 , 0}$ & & \\
\hline
\end{tabular}

Fuente: Elaboración propia a partir del Boletín Estadístico 2009 del Banco de España (año 2010).

mente residentes jubilados) y el segundo formado por nacionales de países subdesarrollados que vienen a nuestro país con el objetivo trabajar para poder mantenerse $\mathrm{y}$, al mismo tiempo, poder enviar remesas a sus familiares que permanecen en el país de origen.

Ahora bien, no todas las nacionalidades realizan el mismo esfuerzo en lo que se refiere a envío de remesas. En la Figura 3 representamos el lugar que ocupa cada país en relación a su número de residentes en España y a su envío de remesas desde la economía española. Los países que se sitúan por debajo de la bisectriz (China, Marruecos y Rumania) tienen un puesto más elevado en envío de remesas que en residentes y los países que se sitúan por encima de la bisectriz tienen un puesto más elevado en residentes que en envío de remesas. Además, una mayor distancia de la bisectriz también indica un menor esfuerzo de la nacionalidad, siendo los casos más extremos Georgia, Bangladesh y Nicaragua.

En todo caso, el volumen total de remesas de cada país depende, entre otros factores, del número de residentes extranjeros de cada nacionalidad, de forma que un colectivo numeroso detentará un mayor volumen de envíos. Para relativizar el peso del envío de remesas de cada nacionalidad vamos a calcular el envío per cápita dividiendo el total de envíos de cada nacionalidad entre la Población Potencialmente Activa (PPA) extranjera de cada nacionalidad, es decir, entre los residentes extranjeros con edades comprendidas entre los 16 y los 65 años. De esta forma incluimos únicamente a los extranjeros que están en edad de trabajar y excluimos a aquellos que no la tienen, evitando así que una nacionalidad con un elevado número de menores o de jubilados quede infravalorada en este cálculo. Los dados de la PPA extranjera los extraemos del Padrón Municipal de Habitantes que publica el Instituto Nacional de Estadística (INE), donde están todos los extranjeros documentados y la mayoría de los indocumentados, evitando que una nacionalidad con un elevado número de irregulares quede sobrevalorada en este cálculo. 
Figura 3

ESFUERZO DE CADA NACIONALIDAD EN EL ENVÍO DE REMESAS

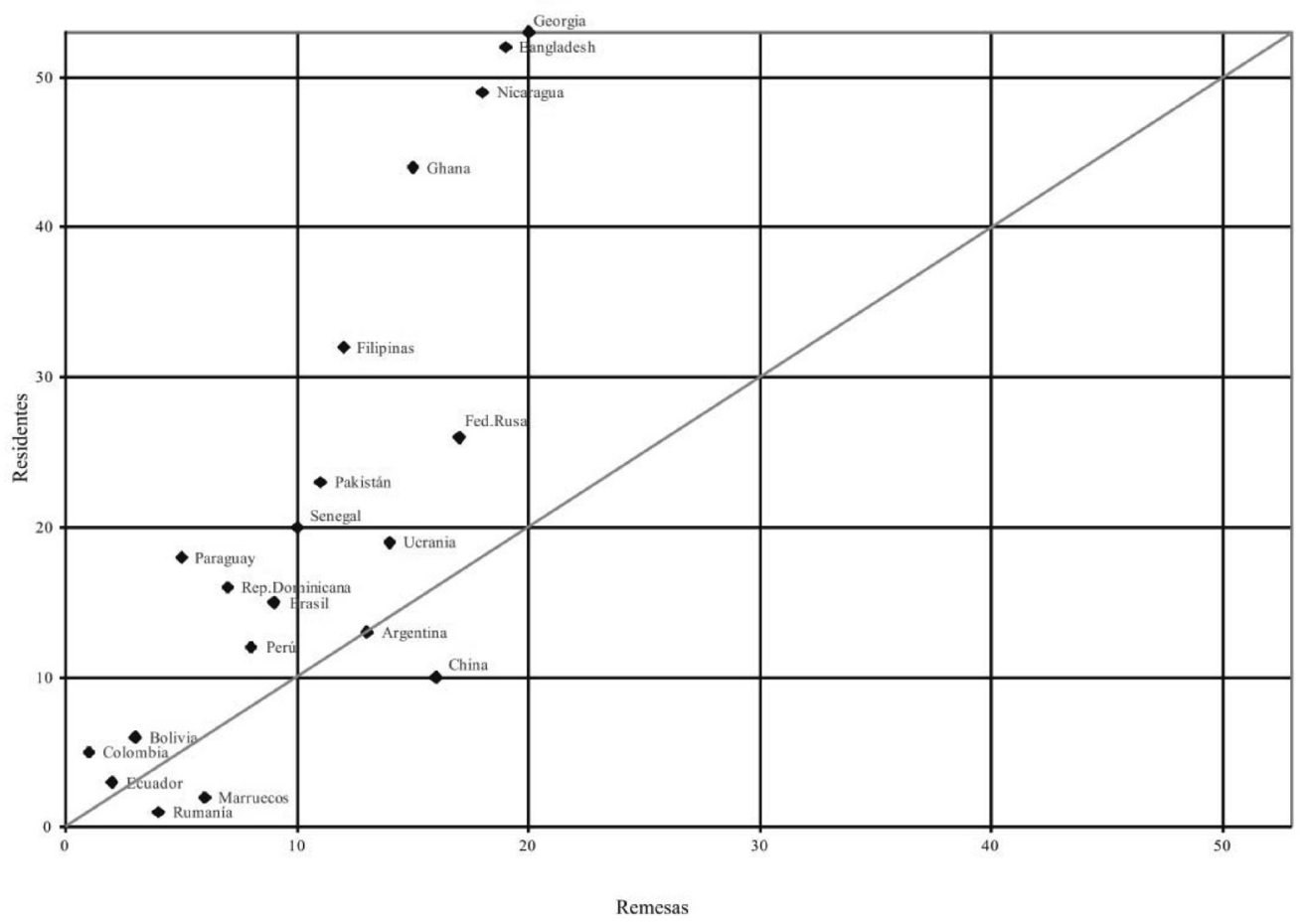

Fuente: Elaboración propia a partir del Boletín Estadístico 2009 del Banco de España (año 2010).

En la Figura 4 podemos diferenciar cuatro grupos según el envío anual de remesas per cápita ${ }^{7}$ El primero, formado por Colombia, República Dominicana, Paraguay, Filipinas y Bolivia, cuyos nacionales envían más de 3.000 euros anuales per cápita. Forman parte del segundo grupo, con envíos de entre 2.000 y 3.000 euros anuales per cápita, Ecuador, Brasil, Pakistán, Senegal y Perú. El tercer grupo (entre 500 y 1.000), lo componen Ucrania, Argentina, Marruecos y Rumania. Por último, con menos de 500 euros anuales per cápita, se encuentran Nicaragua, Bangla Desh, Georgia, Federación Rusa y China.

Dentro de los dos primeros grupos hay un predominio de los países latinoamericanos que, como comentábamos anteriormente, tienen una presencia reciente en nuestro país, lo que aún no les ha posibilitado realizar la reagrupación familiar, hecho que incide positivamente sobre el volumen de remesas que envían. Los países del tercer grupo realizan envíos per cápita mucho más moderados. En el caso de Marruecos, este reducido volumen se podría explicar por dos factores. Por una parte, los marroquíes son los extranjeros que llevan más tiempo residiendo en el territorio español, y diferentes estudios demuestran que existe una correlación negativa entre tiempo de permanencia en la emigración y volumen de remesas enviadas, entre otros motivos porque se consigue la reagrupación familiar; por otra parte, algunas

7 Entre 1.000 y 2.000 euros anuales per cápita se encuentra Ghana. 


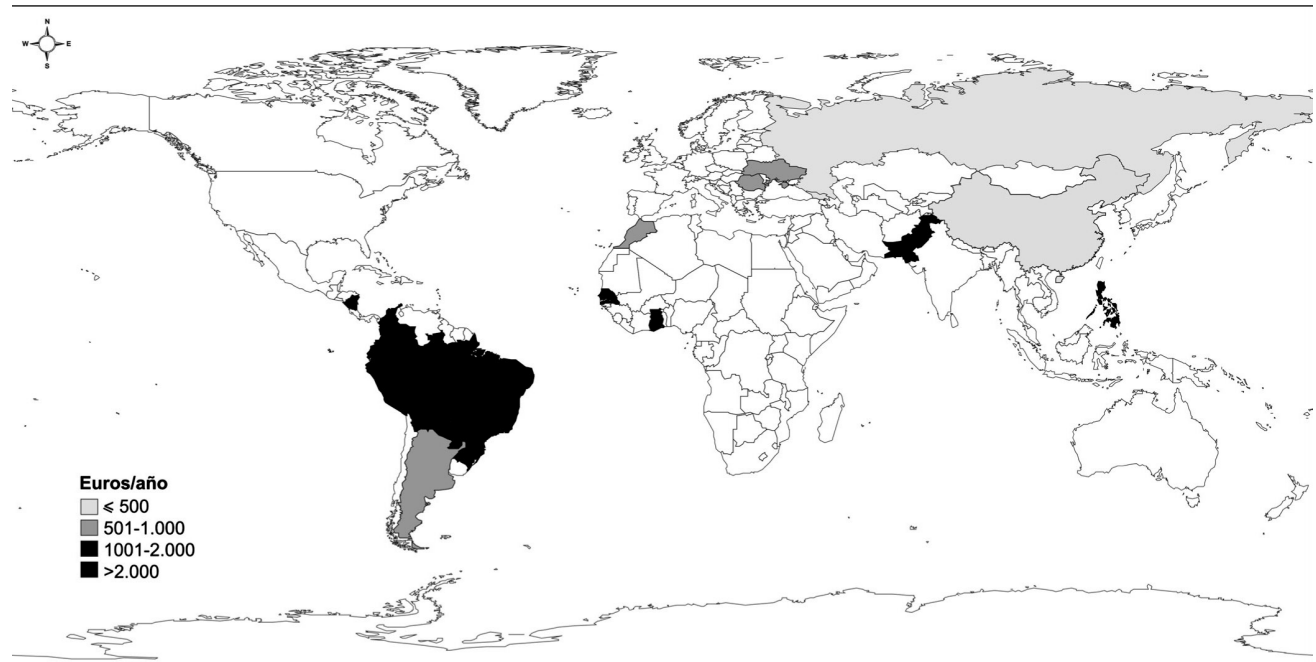

Fuente: Elaboración propia a partir del Boletín Estadístico 2009 del Banco de España (año 2010).

investigaciones indican que los marroquíes canalizan una gran parte de sus envíos a través de vías informales, sobre todo llevando ellos mismos el dinero cuando visitan su país o utilizando a un familiar que va al país, por lo que no aparecen en las cifras oficiales de envíos. El reducido volumen de los envíos per cápita realizados por los rumanos y los ucranianos se explicaría, en gran medida, por su situación familiar, predominando dentro de este colectivo las personas jóvenes y solteras y, por lo tanto, sin el peso de las cargas familiares que supone el cónyuge y los hijos.

La llegada de remesas a los países en desarrollo representa, en la mayoría de los casos, un volumen muy importante de recursos. Para evaluar su importancia, a continuación, para las principales nacionalidades que acabamos de analizar, vamos a cuantificar la importancia que tienen las remesas que llegan desde todo el mundo.

\section{LA IMPORTANCIA DE LAS REMESAS PARA LOS PAÍSES RECEPTORES}

Como comentábamos anteriormente, las remesas suponen importantes ingresos en la economía de algunos países. Para analizar su importancia nos centraremos en los diez países con un mayor volumen de envío de remesas per cápita, calculando el peso porcentual de las remesas, de la Inversión Extranjera Directa (IED) y de la Ayuda Oficial al Desarrollo (AOD) en el Producto Interior Bruto en Paridad de Poder Adquisitivo (PIB PPA) ${ }^{8}$ para el año 2009.

8 PIBpc PPA es el Producto Interior Bruto convertido a dólares internacionales utilizando las tasas de paridad del poder adquisitivo dividido entre el número de habitantes. Un dólar internacional posee el mismo poder adquisitivo respecto del PIB que un dólar de los Estados Unidos en los Estados Unidos. 


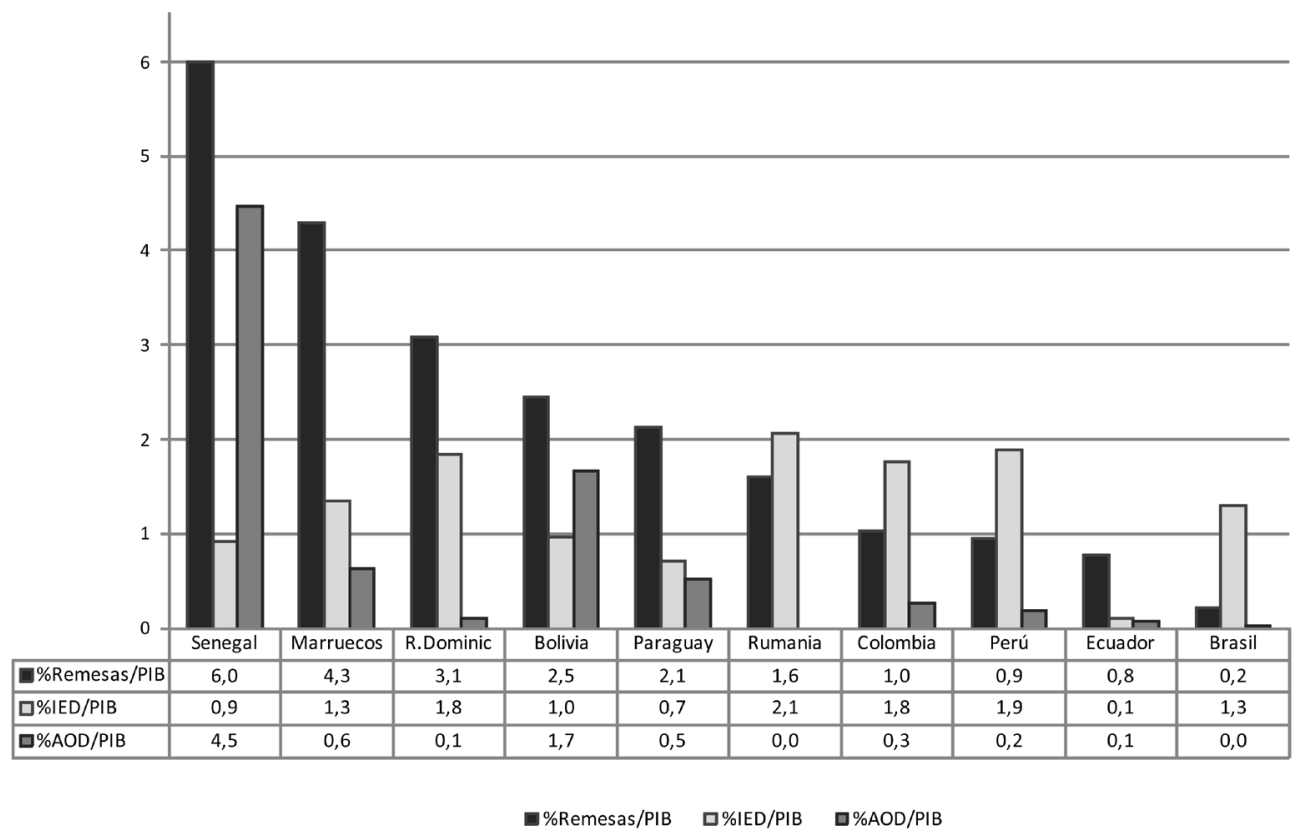

Fuente: Elaboración propia a partir de World dataBank (Banco Mundial).

Tal y como muestra la Figura 5, en el año 2009 el volumen de remesas supuso el 6\% del PIB PPA de Senegal, el 4\% de Marruecos y entre el 2-3\% de la República Dominicana, Bolivia y Paraguay. Además, para la mayoría de los países es mayor el peso de las remesas es mayor que el peso de la IED o que el de AOD.

El flujo de remesas es más estable que el flujo de AOD o de IED. En la Figura 6a representamos los flujos de entrada de estas tres variables para los países en desarrollo de bajo ingreso y en la Figura 6b para los países en desarrollo de ingreso medio. Al realizar la comparación entre ambas figuras observamos que, por una parte, para los países de ingreso medio el flujo de remesas es más importante que la AOD o la IED, pero para los países de bajo ingreso es más importante la AOD. Por otra parte, en los tres flujos se nota la incidencia de la crisis económica actual, de forma que los tres reducen su volumen, pero es mucho más significativa la reducción de la IED que la reducción de las remesas.

La mayoría de los inmigrantes que residen en España proceden de países subdesarrollados. Algunos datos publicados por el Banco Mundial pueden ayudarnos a ilustrar mejor la situación de subdesarrollo de estos países. Por ejemplo, en el 2004, en Rumania sólo el 57\% de la población tenía acceso al agua potable en la cantidad necesaria, en Marruecos sólo el $52 \%$ de la población adulta estaba alfabetizada y en Perú el 53\% de la población estaba por bajo de la línea de pobreza. El año 2005, la esperanza de vida en Senegal se situaba nos 56 años y en Bolivia la tasa de mortalidad de los menores de 5 años era del 65 por mil. 
Figura 6a

EVOLUCIÓN DE LAS REMESAS, IED YAOD EN LOS

PAIISES DE BAJO INGRESO (MILLONES DE US\$)

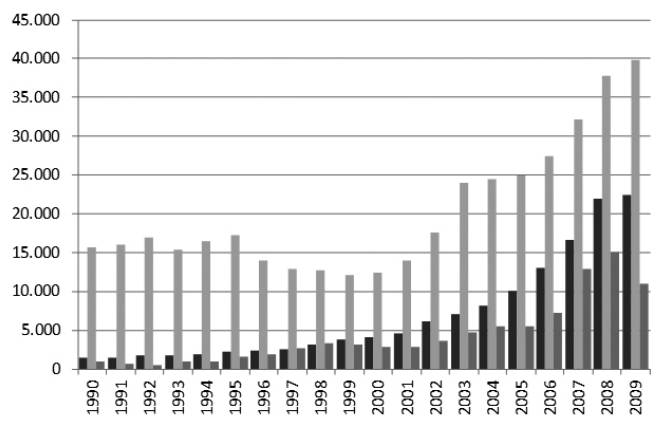

- Remesas AOD UIED
Figura 6b

EVOLUCIÓN DE LAS REMESAS, IED YAOD EN LOS

PAISSES DE BAJO MEDIO (MILLONES DE US\$)

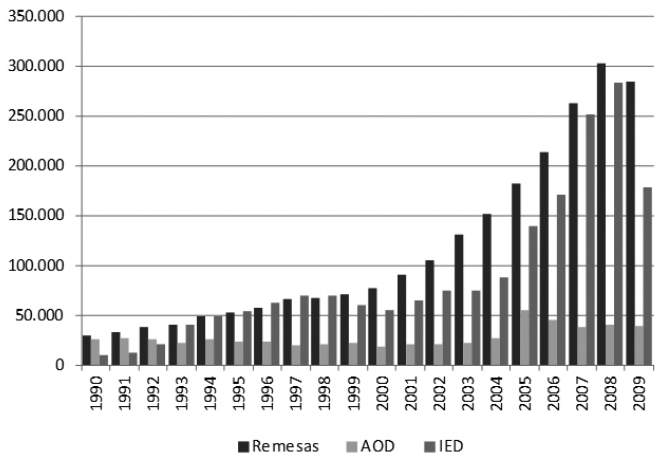

Fuente: Elaboración propia a partir de World dataBank (Banco Mundial).

Desde el punto estrictamente económico, para hacernos una idea del diferencial de ingresos que separa a la economía española de las economías del Tercer Mundo, en la Tabla 3 aportamos datos del PIB per cápita PPA de algunos de estos países y calculamos su proporción con el PIB per cápita PPA español para el año 2009. Así, en el caso de Senegal la relación es de 1 a 18, o lo que es el mismo, un español tiene 18 veces más ingresos que un senegalés. En el caso de Bolivia, Marruecos y Paraguay la relación es de 1 a 7. Así, a pesar de los bajos salarios existentes en el mercado laboral español, desde el punto de vista estrictamente económico, trabajar en la economía española es una importante fuente de ingresos para los familiares de los inmigrantes asentados en nuestro país.

Tabla 3

PIB PC ESPAÑOL EN RELACIÓN AL PIBPC DE CADA PAÍS (AÑO 2009)

\begin{tabular}{|l|r|r|}
\hline PIB pc PPA & & España/País \\
\hline Senegal & 1.806 & 18 \\
\hline Bolivia & 4.426 & 7 \\
\hline Marruecos & 4.575 & 7 \\
\hline Paraguay & 4.778 & 7 \\
\hline Ecuador & 8.280 & 4 \\
\hline Rep. Dominicana & 8.446 & 4 \\
\hline Perú & 8.647 & 4 \\
\hline Colombia & 8.870 & 4 \\
\hline Brasil & 10.427 & 3 \\
\hline Rumania & 13.198 & 2 \\
\hline España & 32.545 & \\
\hline
\end{tabular}

Fuente: Elaboración propia a partir de World dataBank (Banco Mundial). 


\section{CONCLUSIONES}

España ha pasado de ser un país emisor de emigrantes y un foco receptor de remesas en la década de 1960 a ser un receptor de inmigrantes y emisor de remesas desde comienzos del siglo XXI. Actualmente, los principales países receptores de las remesas enviadas desde la economía española son los de América del Sur, destacando las nacionalidades que también tienen una mayor presencia dentro del conjunto de residentes extranjeros. De todas formas, el análisis del envío de remesas por nacionalidades nos permitió observar la importancia de otros países.

Uno de los factores que condiciona el volumen de remesas de cada país es el número de residentes extranjeros de esa nacionalidad, si bien existen otras variables que influyen en la reducción de las remesas (reagrupamiento familiar) o en el aumento de las mismas (familias extensas en el país de origen). Además, otras variables, como el estado civil del extranjero, pueden tener una incidencia positiva en los envíos (si predominan los casados) o negativa (si destacan los solteros). De hecho, cuando calculábamos el envío de remesas per cápita según nacionalidad observábamos que países con un valor bajo en el total de envíos tenían un alto valor en los envíos per cápita, resultado que estaba condicionado por las mencionadas variables. Debemos tener en cuenta que estos cálculos están realizados con datos oficiales, donde el envío de remesas está subestimado. De esta forma, para cada nacionalidad el envío real de remesas se alejará del oficial cuanto mayor sea el envío a través de canales informales. Así, de cara al desarrollo de futuras investigaciones, y dadas las deficiencias detectadas en las fuentes estadísticas oficiales, también sería importante estimar el envío informal de las remesas a través de estudios de campo, como realización de encuestas a las diferentes nacionalidades de inmigrantes, por ejemplo.

Con este artículo intentamos hacer una primera aproximación al difícil estudio del envío de remesas. Dado que las remesas tienen para muchos países del Tercer Mundo una mayor importancia que la entrada de IED o que la AOD, sería importante profundizar en este análisis, investigar el uso de las remesas en cada país y tratar de diseñar medidas que canalicen parte de las remesas hacia el desarrollo de estas economías. Efectivamente, las remesas pueden incidir positivamente sobre el crecimiento económico de los países que las reciben, pero para que esto suceda deben diseñarse políticas para facilitar este proceso. Por una parte, los gobiernos de los países receptores de remesas deben articular mecanismos para canalizar las remesas hacia usos productivos y, por otra parte, las comunidades emigradas deben elaborar estrategias organizativas que promocionen el desarrollo en sus países de origen. Además, el efecto positivo de las remesas se vería aumentado si existiera una mayor cooperación al desarrollo con los países de emigración. Sin embargo, cuando las remesas no se utilizan para usos productivos, su repercusión puede ser muy negativa, ya que reducen el ahorro y el esfuerzo productivo de las familias beneficiarias, afectando negativamente al crecimiento y al desarrollo del país, aumentando la desigualdad entre las familias que las reciben y las que no y generando más emigración.

Finalmente, cabe señalar que en el momento en que finalizarnos este artículo, nos encontramos ante un nuevo escenario. La crisis económica actual y el desempleo están provocando un giro en los flujos migratorios de nuestro país, de forma que no sólo se 
constata un regreso de los inmigrantes a sus países de origen sino que además se están registrando nuevas salidas de españoles hacia otros países. Sin embargo, existe un factor diferencial en los flujos migratorios actuales de los españoles y es que, a diferencia de lo que sucedía en la década de 1960, actualmente los que emigran son personas con altos niveles de cualificación, lo que sin duda alguna tendrá repercusiones negativas para el futuro de nuestro país.

\section{BIBLIOGRAFÍA}

APARICIO GÓMEZ, R. (2003): «O impacto ecoómico da emigração: Custos para o Estado e movimento de consumo e salários - Espanha» en Impacto da imigração em Portugal nas contas do Estado (Corrêa D’Almeida, A., coord.). Lisboa. Alto-Comissariado para a Imigração e as Minorias Étnicas, 85-124.

BANCO DE ESPAÑA: Boletín Estadístico. Madrid, Banco de España (varios años).

COLECTIVO IOÉ (http://www.nodo50.org/ioe).

BANCO MUNDIAL: World dataBank (http://datos.bancomundial.org/)

BERGER, J. y MOHR, J. (2002): Un séptimo hombre. Madrid. Huerga y Fierro Ediciones.

CÀNOVES VALIENTE, G. y BLANCO ROMERO, A. (2009): «Turismo, mercado de trabajo e inmigración en España. Un análisis de la situación en las Comunidades de Murcia, Canarias, Valencia y Andalucía». Boletín de la Asociación de Geógrafos Españoles, n ${ }^{\circ}$ 50, 259-280.

CHAMI, R., FULLENKAMP, C. y JAHJAH, S. (2003): «Are Immigrant Remittances Flows a Source of Capital for Development?», Working Paper, ${ }^{\circ}$ WP/03/189. Washington, D.C.: International Monetary Fund.

CRAFTS, N. y TONIOLO, G. (ED.) (1996): Economic Growth in Europe since 1945. Cambridge. Cambridge University Press.

DJAJIC, S. (1986): «International migration remittances and welfare in a dependent economy». Journal of Development Economics, n 21, 229-234.

DOCQUIER, F. y MARFOUK, A. (2004): «Measuring the International Mobility of Skilled Workers (1990-2000) - Release 1.0». Documento de trabajo del Banco Mundial sobre investigaciones relativas a políticas, $\mathrm{n}^{\circ} 3381$. Washington, D.C.

DOCQUIER, F. y BHARGAVA, A. (2006): «The Medical Brain Drain: A New Panel Dataset on Physicians'Emigration Rates (1991-2004)». Banco Mundial. Washington, D.C.

ELBADAWI, I.A. y ROCHA, R. (1992): «Determinants of Expatriate Workers' Remittances in North Africa and Europe». Policy Research Working Paper, $\mathrm{n}^{\circ}$ 1038. Washington, D.C.: World Bank.

GÓMEZ GALÁN, M., DAVID, I., ALBARRÁN CALVO, M., MALGESINI REY, G. y EL HARCHI BIRO, Y. (2008): Migraciones y codesarrollo en la relación entre la Unión Europea y América Latina y el Caribe. Celare. Santiago de Chile.

GONZÁLEZ PÉREZ, J.M. (2008): «La aparición reciente del fenómeno inmigratorio extranjero en Galicia. Características e impronta espacial». Boletín de la AGE, n 48, 247-275.

INSTITUTO NACIONAL DE ESTADÍSTICA: Padrón Municipal de Habitantes. Madrid. Instituto Nacional de Estadística. 
IZQUIERDO ESCRIBANO, A., LÓPEZ DE LERA, D. y MARTÍNEZ BUJÁN, R.: (2003): «The favorites of the Twenty-First Century: Latin American Inmigration in Spain». Studi Emigrazione, $\mathrm{n}^{\circ} 149,98-124$.

MÁRMORA, L. (2002): Las políticas de migraciones internacionales. Buenos Aires. Paidós.

MINISTERIO DEL INTERIOR (1997): Anuario Estadístico de Extranjeros 1996. Madrid. Ministerio del Interior.

MINISTERIO DE TRABAJO Y ASUNTOS SOCIALES (2010): Anuario Estadístico de Inmigración 2009. Madrid. Ministerio de Trabajo y Asuntos Sociales.

MORENO FUENTES, F.J. y BRUQUETAS CALLEJO, M. (2011): Inmigración y Estado de bienestar en España. Barcelona. Obra Social la Caixa.

LEVITT, P. (2001): The Transnational Villagers. Berkeley and Los Angeles. University of California Press.

LÓPEZ SALA, A.M. (2005): Inmigrantes y Estados: la respuesta política ante la cuestión migratoria. Barcelona. Anthropos Editorial.

LUCAS, R. y STARK, O. (1985): «Motivations to remit: evidence from Botswana». Journal of Political Economy, n 3, 901-918.

OCDE: International Migration Data (http://www.oecd.org)

OROZCO, M. y ROUSE, R. (2007): «Migrant hometown associations and opportunities for development: a global perspectivein». Migration Information Source. Migration Policy Institute.

RODRÍGUEZ, V., FERNÁNDEZ MAYORALAS, G., CASDO DÍAZ, M. A. y HUBER, A. (2005): «Una perspectiva actual de la migración internacional de jubilados a España», en La Migración de europeos retirados en España (Rodríguez Rodríguez, V., Casado Díaz, M.Á. y Huber, A., ed.). Madrid. CSIC, 15-45.

SEBASTIÁN, M. (2006): Inmigración y economía española: 1996-2006. Documento publicado pela Oficina Económica del Presidente del Gobierno (15 de Novembro de 2006).

SEERS, D. (1981): «La periferia europea», en La Europa subdesarrollada. Estudios sobre las relaciones Centro-Periferia (Seers, D.). Madrid. H. Blume Ediciones.

TELLO, P. (2006): Las remesas de emigrantes en la Balanza de Pagos de España: Consideraciones conceptuales y prácticas. Madrid. Departamento de Balanza de Pagos del Banco de España.

VERDUGO MATÉS, R.M., LOIS GONZÁLEZ, R. y ALDREY VÁZQUEZ, J.A. (2004a): «Os residentes estrangeiros em Espanha». GeoINova (Universidade Nova de Lisboa), ${ }^{\circ}$ 8, 2004, 11-33.

VERDUGO MATÉS, R.M. y ALDREY VÁZQUEZ, J.A. (2004b): «Iberoamericanización de la inmigración española a comienzos del siglo XXI». Cuadernos Americanos (Universidad Autónoma de México), nº106, Julho-Agosto 2004, 149-168.

ZAMORA, J. A. (2003): «Globalización y migraciones. Una mirada desde Europa solidaria con el Sur». Realidad. Revista de ciencias sociales y humanidades. UCA /El Salvador, vol. 95,24 pp.

ZELINSKI, W. (1971): Introducción a la Geografía de la Población. Barcelona. Ed. Vicencs Vives. 